\title{
Paisaje táctil. Sobre la construcción háptica del paisaje
}

\author{
Pilar Correa Silva* \\ Germán González Quiroz**
}

Recibido 22 de abril de 2019; aceptado 16 de junio de 2019

\begin{abstract}
This work considers the problems that persons with blindness face on a daily basis in the handling of spatial and time dimensions in the surroundings they live in, and in how, through the use of suitable technical images, they can set up frameworks of orientation and information for them, thus encouraging them to imagine for themselves the space lived in, including that of the landscape, and their possibilities for action in it.

Concentrating on geographic space from the landscape viewpoint allows us to look carefully at the nature of human life without light, in order to be able to understand spaces beyond the body's reach as interpreted by the blind, providing an aesthetic approach to that experience.

Key words: Landscape, technical image, blindness, multisensory design, imagination, tactile sense.

Resumen

Este trabajo reflexiona sobre los problemas que enfrentan cotidianamente las personas con ceguera en el manejo de la dimensión espacio-temporal del entorno que habitan, y en el cómo a través de la mediación de imágenes técnicas apropiadas se pueden elaborar marcos de orientación e información, que favorecen su propia imaginación del espacio vivido, incluyendo el del paisaje, y sus posibilidades de accionar en él.
\end{abstract}

* Departamento de Diseño, Centro de Cartografía Táctil, Programa Institucional de Fomento a la Investigación, Desarrollo e Innovación, Universidad Tecnológica Metropolitana, Chile, correo electrónico: pcorrea@utem.cl

** Departamento de Artes Visuales, Facultad de Artes, Universidad de Chile, Chile, correo electrónico: ggonzalezquiroz@uchile.cl 
El ocuparnos del espacio geográfico, desde el enfoque del paisaje, nos permitió reflexionar sobre la naturaleza de la vivencia humana sin luz, de modo de poder comprender la experiencia del espacio distal interpretado por los ciegos, aportando una aproximación estética a dicha experiencia.

Palabras clave: paisaje, imagen técnica, ceguera, diseño multisensorial, imaginación, sentido táctil.

\section{Resumo}

Este trabalho reflete sobre os problemas enfrentados diariamente por pessoas com deficiência visual no manejo da dimensão espaço-temporal do ambiente em que eles habitam e em como, por meio da mediação de imagens técnicas apropriadas, marcos de orientação e informação podem ser elaborados, favorecendo a própria imaginação do espaço vivido, incluindo o da paisagem e as possibilidades de atuar sobre ela.

Ao tratar do espaço geográfico, a partir do enfoque da paisagem, nos permitiu refletir sobre a natureza da experiência humana sem luz, a fim de compreender a experiência do espaço distal interpretado pelos cegos, proporcionando uma abordagem estética a essa experiência.

Palavras chave: Paisagem, imagem técnica, cegueira desenho multissensorial, imaginação, sentido táctil.

\section{Introducción}

El hombre para sobrevivir, como muy bien lo describe este término compuesto: "sobre-vivir", lo hace estando sobre un lugar, un espacio vivido como lo plantea MerlauPonty, un espacio geográfico. En él, a lo largo de la historia, los seres humanos han ido plasmando la relación con su propio entorno, transfigurándolo y a su vez estableciendo su conexión con el resto del mundo. Esta comunicación ser humano-entorno se continúa dando en la actualidad, fuertemente condicionada por los medios tecnológicos. Sin embargo, a pesar de la irrupción de la tecnología, la recogida de información sigue ocurriendo a través de los sentidos, como los principales instrumentos a través de los cuales los sistemas perceptivos y cognitivos la procesan.

Esta relación comunicativa que se da entre el ser humano y su entorno no es directa, como lo planteó Vilém Flusser: "Las imágenes son intermediarios entre el mundo y los hombres. El hombre ex-iste, es decir, no accede al mundo de forma inmediata, sino a través de las imágenes, que le permiten imaginarlo" (2001: 13). Según este mismo autor "las imágenes son mediaciones entre el sujeto y el mundo objetivo, y en cuanto tales están sometidas a una dialéctica interna: se ponen delante de los objetos que han de presentar” (2016: 21). He aquí nuestra interrogante: ¿Cómo generan las imágenes propias de su entorno, sus imágenes mentales, las personas sin información visual? ¿Cómo resuelven las formas de los objetos que no pueden ser 
alcanzados por las extensiones de su corporalidad? ¿Cómo se los pueden imaginar? ¿Qué papel juegan las mediaciones técnicas representativas del entorno?

Lo primero que queremos subrayar es que en estas interrogantes existe una desigualdad entre el espacio vivido por el cuerpo del perceptor con discapacidad visual, que comparte con otros objetos, y el espacio sensible representado en su imaginación; las sensaciones del perceptor vidente comparadas al que no ve difieren, el adentro es diferente que el afuera, no son equivalentes.

Examinamos, entre otros, los aportes de Vilém Flusser, en cuanto a la capacidad humana de generar imágenes propias, internas, que le permitan ubicarse en el espacio de "afuera". Por investigaciones previas realizadas en el Centro de Cartografía Táctil, hemos comprobado que dichas imágenes acompañan posteriormente la dimensión temporal de la percepción de las personas con ceguera (Correa, 2015: 86). En un comienzo nos focalizamos, de modo especial, en el concepto de imaginación que propuso dicho autor, para posteriormente ocuparnos de cómo las personas, frente a la carencia de los estímulos visuales, se pueden valer de las capacidades transcodificadoras de las imágenes táctiles (entendidas desde ahora como imágenes técnicas) para que la comprensión del entorno les sea posible.

Respecto al concepto de imaginación Jean-Paul Sartre describió en 1940 algunas de las características de la imagen mental, a través de la descripción de la función "irrealizante" de la consciencia, a la que él identificó justamente con la imaginación, y de su correlativo noemático, lo imaginario. Sartre también estableció una importante relación entre la naturaleza y su imagen mental (o imaginaria), considerando a esta última como un verdadero analogón de la primera. También argumentó que ambos mundos, el imaginario y el real, están constituidos por los mismos objetos, sólo varía el agrupamiento y la interpretación de estos objetos. Lo que define al mundo imaginario como al universo real, es una actitud de consciencia. En la generación de imágenes mentales otorga tanto valor al movimiento del cuerpo como al de las manos, destacando que, en la imagen mental "se trata de alcanzar el objeto como síntesis de percepciones, es decir, en su forma corporal y sensible" (Sartre, 1997: 117) Ernest Gombrich, coincidiendo, afirmó:

...si intentamos analizar nuestras imágenes mentales para descubrir sus constituyentes primarios, encontramos que se componen de datos sensorios derivados de la visión y de recuerdos del tacto y del movimiento (1979: 28).

Entonces, las imágenes que elaboramos día a día dependen del empleo de complejos y al mismo tiempo colaborativos sistemas sensoriales, que recogen la información para su procesamiento interior. La información del ambiente la recogemos no solo de modo visual sino además a través de los sonidos, los olores, sabores, texturas y la vivencia del propio cuerpo y su movimiento. Sin embargo, a causa de nuestra evolución como especie en la vida moderna, estamos condicionados por el uso y abuso de las imágenes visuales. De esta manera, es a partir casi exclusivamente del 
habitar visual que podemos acceder a los otros planos del convivir en sociedad. Florentino Blanco y Eugenia Rubio, en sus estudios de la ceguera, se refieren a esta temática:

La enorme pregnancia del sistema visual como mecanismo de precepción distal y su alto poder de resolución espacial generan con facilidad < atribuciones de externabili$\mathrm{dad}>$ sobre el contenido de la experiencia individual y permiten que la percepción visual resulte más vinculante que otros tipos de experiencia sensorial (1993: 106).

La actual cultura de la imagen fue augurada por varios autores, como Flusser, quien indica que hay una transición de la cultura del texto a la cultura de la imagen técnica (2001), o como Giovanni Sartori, que plantea que el homo sapiens, producto de la cultura escrita, ha sido destronado por el homo videns, producto de la cultura de la imagen (1998: 11). Hoy vivimos inserto en la cultura que ha sido descrita como cultura audio-visual, preponderante en los nuevos medios. Gilbert Cohen-Séat, en 1959, acuño el término iconosfera, el mismo que posteriormente Román Gubern definió como:

ecosistema cultural formado por los mensajes icónicos audiovisuales que envuelven al ser humano, basado en interacciones dinámicas entre los diferentes medios de comunicación y entre éstos y sus audiencias (1996: 183).

En este sistema envolvente, compuesto por un sinfín de imágenes visuales y sonidos, se deben mover, estudiar, trabajar y disfrutar de su tiempo libre, las personas carentes de visión ocular.

Junto con lo anterior, queremos de modo particular, fijar nuestra atención en el concepto de paisaje, como una forma especial de composición y representación del espacio. A través de él introduciremos, en la parte final de este artículo, unas cuantas ideas que nos acerquen, de manera general, a la experiencia estética involucrada en la exploración (o lectura) de los diseños táctiles por parte de las personas ciegas o con baja visión.

Desarrollaremos esta aproximación a la estética implicada en la recepción de los diseños táctiles dedicados al paisaje, específicamente los generados a partir de un proceso de grabado digital por desbaste empleando una router $\mathrm{CNC}^{1}$ sobre láminas de Krion, como una manera de sumar una variable sensible que regularmente queda fuera de las discusiones en este ámbito del conocimiento.

\section{Paisaje e imagen}

Que más natural que el paisaje, diremos a menudo sin caer en la cuenta de su construcción como imagen. $\mathrm{Y}$ esto es posible decirlo en el caso de su aprehensión 
espontánea, como vista de turista, y sobre todo en el caso de su apreciación como representación, composición o producción visual. Sean estas plasmadas como pintura, dibujo, grabado o fotografía, a los que se pueden añadir otros medios que sirven al mismo fin, como el cine, el video o la animación digital, lo cierto es que pocas veces reparamos en el complejo producto que reclama nuestros sentidos. La imagen como constructo y el paisaje como uno de sus géneros, continúan experimentándose como mediaciones que exigen distancia respecto a nuestro entorno. Y esto es porque no equivalen a lo mismo.

Augustin Berque en un artículo titulado "En el origen del paisaje" apunta a la misma diferencia, contrastando "una representación por un lado (el paisaje-imagen)" con "un entorno real por otro (el paisaje a escala natural)" (1997: 7). Este contraste no significa que la naturaleza deje de existir como paisaje, sobre todo si lo afirmamos desde una perspectiva positivista, para la cual, sigue Berque, "no puede dejar de haber paisaje, ya que [...] el entorno resulta visible siempre y en todas partes; por tanto, siempre y en todas partes hay paisaje" (1997: 8). Pero aclara también que el énfasis científico está en la evidencia mensurable de lo que está, y cae ante nosotros como objeto de estudio; es decir como ob-jectum (arrojado ante), marcando radicalmente su separación del sujeto que lo percibe, tal como ocurre dentro de la tradición y cultura occidental (Van Lier, 1971). Volveremos sobre este punto más adelante.

Al desarrollar la reflexión anterior, se podría llegar a la conclusión de que el paisaje como representación sólo sería compresible a partir de una aprehensión subjetiva, y el paisaje como naturaleza a partir de otra objetiva. Pero seguramente esta sería una conclusión apresurada, ya que ambas miradas tienden a mezclarse necesariamente en la existencia material de las sociedades (Berque, 1997). De esta manera sobrevive un componente objetivo en la representación subjetiva del paisaje (la misma naturaleza), como no es extraño el elemento subjetivo en la concepción objetiva del entorno (la misma humanidad). El paisaje como imagen de representación, no impide atender al paisaje como evidencia conmensurable. Deberemos buscar un poco más para encontrar una mejor explicación de las diferencias entre estas dos miradas.

Gombrich nos ofrece en su trabajo sobre "La teoría del arte renacentista y el nacimiento del paisaje" (2000), la siguiente constatación sobre el origen del paisaje en Europa: “...de todos los géneros que los "especialistas" del siglo XVI empezaron a cultivar en el norte, el paisajismo es sin duda el más revolucionario" (108). Añadiendo que con este empuje el género se fue convirtiendo en una verdadera "institución", libre de sujeciones y dependencias, ya sea didácticas o valóricas, cultivadas en el arte medieval. Esto posibilitó su estabilidad y reconocimiento como arte "puro" y posibilidad comercial para los que lo produjeron como oficio. Asimismo, Gombrich nos señala que si bien la práctica del paisaje estuvo radicada en el norte europeo (Países Bajos y Alemania), su explicación estética y determinación como género se 
concretó en el sur renacentista (Venecia e Italia). Entre los antecedentes que emplea para tal aseveración destaca una referencia a Leonardo, y su convencida descripción de lo que un pintor podía realizar dedicando su arte a los temas de la naturaleza:

En realidad, todo que exista en el universo en potencia o en acto, o en la imaginación, él lo tiene primero en su mente y luego en sus manos, y estas [imágenes] son tan excelentes que presentan la misma armonía proporcionada al primer vistazo, como es propio de las cosas mismas... (112).

Continuando con la concepción y producción del paisaje en Europa, podríamos añadir una reflexión, en la línea que Leonardo parece sugerir, sobre la evolución de la misma imagen como paradigma de realidad, en reemplazo de la experiencia y la mirada directa sobre la naturaleza. Este pensamiento tuvo en Flusser uno de sus más interesantes cultores. Para este autor la evolución del conocimiento humano y su lenguaje, estuvo unido a su capacidad de separarse de la experiencia sensible, reemplazándola por sus maneras de referirse a ella. En este sentido elabora una tesis en la cual la comunicación humana fue paulatinamente prescindiendo y abstrayéndose de la presencia de lo natural. Esta evolución que en su primer estadio cubría toda la vivencia espacio temporal y directa de la naturaleza (experiencia cuatridimensional), pasa a otra de carácter tridimensional (la elaboración de objetos), y después a una bidimensional (la elaboración de imágenes), hasta llegar a la forma unidimensional (la invención de la escritura) (Becker, 2015). Finalmente, la tesis evolutiva de Flusser apunta a un cambio radical en el recorrido de la comunicación humana, representado por el advenir de la imagen técnica (la fotografía como primera). Su interpretación de la misma no deja de ser revolucionaria, ya que a diferencia de la imagen tradicional (si se quiere análoga) la técnica ya no se refiere ni menos tributa a la realidad sensible, sino que a las teorías científicas que le dan origen. Así pues, en este tipo de imágenes (la digital sería una de las últimas) lo que vemos como parecido o referencia de lo sensible es el resultado de su programación y codificación anterior, adquiriendo así un estatus como conceptos transcodificados. Por lo tanto, si estas imágenes equivalen a un lenguaje, este vale por otro que lo fundamenta; es decir, se convierte en un lenguaje de lenguaje.

Este resultado permite afirmar al mismo Flusser el arribo de un postrero estadio evolutivo de la comunicación humana: la dimensión cero. En ella se colmarían todas las distancias respecto a la experiencia sensible de la naturaleza, al punto de no necesitarla para referirnos a ella. Por supuesto, este estadio aun no llegaría en plenitud, y de hecho las etapas anteriores aun sobrevivirían, traslapándose como ya lo hicieron antes, ya que no se debe entenderlas como fases estancas y aisladas una de otra. El verdadero desafío por venir sería la toma de conciencia de la importancia de esta 
última evolución, y la preparación consecuente para administrarla en favor de la humanidad, por medio del dominio de un nuevo tipo de pensamiento basado en dichas imágenes. Sería la diferencia entre progreso o alienación según el mismo autor.

No es el caso de este artículo acompañar el pensamiento de Flusser hasta sus últimas consecuencias, no obstante, resulta un interesante aporte para poner en perspectiva la identidad de las imágenes, y su laborioso y complejo progreso epistemológico hasta nuestros días. Sus reflexiones nos pueden servir también para enriquecer nuestro intento de exponer el concepto y el género del paisaje táctil. Al respecto, si nos fijamos en lo que él denomina el estadio de la "imagen tradicional", coincidiríamos nuevamente con la cita de Leonardo y las precisiones de Gombrich sobre dicha "especialidad". Entenderíamos de este modo y de mejor manera el sentido de sus convenciones, al interpretarlas como la cifra y el procedimiento que materializaba el concepto de paisaje que el artista plasmaba en el lienzo (u otro soporte), teniéndolo "primero en su mente y luego en sus manos". Este logro en la comunicación de nuestro entorno representa la capacidad de imaginar para Flusser, que es ante todo el acto de plasmar sobre una superficie una representación de la realidad. Pero, debemos precisar, en un sentido que abstrae la mirada del natural, alejándonos de su experiencia inmediata.

\section{Habitar el paisaje y la capacidad interpretativa de la especie humana}

No podemos olvidar que todo conocimiento se gesta a partir de los sentidos. Así como lo planteara Aleksandr Luria "Las sensaciones constituyen la fuente principal de nuestros conocimientos del mundo exterior y de nuestro propio cuerpo" (1981: 9). Y son estas las que unen al hombre con el mundo exterior (1981: 11), gatillando el proceso de la percepción. Tradicionalmente, esta ha sido estudiada en la dualidad sujeto-objeto y en relación al mundo del observador, entendiendo que está "ahí afuera", que es un mundo pre-dado, independiente y plagado de otros objetos.

En el siglo XX encontramos la obra del filósofo alemán Edmund Husserl, que al cuestionar la división entre sujeto y objeto inició una corriente filosófica que llamó "fenomenología", desde la cual reparó en la relación entre el cuerpo y el mundo, donde la conciencia era la conexión. Esta línea de pensamiento encontró continuidad en la propuesta del filósofo francés Merleau Ponty, quien afirmó la trascendencia del cuerpo humano como una totalidad, y entendió al sujeto como una unidad corpórea, parte de un sistema. Estableció también que el único camino para el encuentro, para el contacto entre el cuerpo y la naturaleza, es la percepción, considerándola además el núcleo del conocimiento.

Ponty lo sintetizó en el juego de palabras "ser-del-mundo". Ser y mundo, como un sistema que se conforma en el habitar el espacio a través de la acción, dándose así 
el espacio vivido, actuado. Este se vuelve fundamental para el individuo que lo organiza; el resto, el espacio no habitado, es inexistente para él. En la misma línea, SamiAli nos plantea que:

Lo que nace en el cuerpo también se sitúa fuera de él. Todo lo que acontece en el mundo ocurre en el cuerpo. La superficie del cuerpo es la del mundo, lo visible es una piel simultáneamente vuelta hacia adentro y hacia fuera (Sami-Ali, 1984: 82).

De este modo y como producto del actuar, según Ponty, "el cuerpo vive en un espacio". Y añade: "El mundo se ordena entorno mío y empieza a existir para mí" (1994: 9). El cuerpo se considera como una totalidad, como una realidad activa que consiste en significar, estableciendo una dialéctica cuyos componentes son los objetos fenomenales y la acción siempre está orientada al mundo (el mundo vivido). Se reconoce así la multisensorialidad del cuerpo, la importancia de la experiencia, la acción y los diferentes lenguajes con los cuales el cuerpo interactúa y se comunica.

Así el ser humano según su propia estructura — incluido su sistema nerviosoentra en contacto con el espacio vivido. Se produce de esta manera un constante acoplamiento estructural con el ambiente, a través de todos sus sentidos, encargados de gatillar en conjunto el fenómeno del percibir. Esta es la base por la cual se cimienta el proceso del conocer, quedando evidenciado por qué la metáfora representacionista del conocimiento - basada fundamentalmente en la visión - no reconoce toda la información que el sistema nervioso recoge y procesa, para fundar sobre ella el fenómeno cognitivo. Este nuevo enfoque desde la biología del conocimiento es un intento, como dijeron Humberto Maturana y Francisco Varela, de reformular la percepción como "no-representacional", trasladando el centro de interés a la capacidad interpretativa del ser vivo. Dicho enfoque concibe al hombre no como un agente que descubre y observa el mundo, sino que lo constituye, que lo habita, que debe por tanto decodificarlo continuamente en su constante interacción con él (1984: 111). A esta decodificación Varela la llamó el punto de vista de la "enacción", (2005: 89), concepto a través del cual afirmó que la percepción es una acción guiada perceptivamente, acción que emprende con todo su ser corpóreo. Es decir que su explicación se encuentra más en las bases biológicas del conocimiento humano, y en esta necesidad de acoplamiento, que podría verse beneficiada por algún mecanismo que optimice el actuar, planteando "que nuestra cognición emerge del trasfondo de un mundo que se extiende más allá de nosotros, pero que no existe al margen de nuestra corporización" (Varela, Thompson, 2005: 203)

En relación a lo anterior, investigaciones recientes en el campo de la cognición se han enfocado en la importancia del "aprendizaje encarnado", el que se refiere a entornos educativos que involucran a todo el cuerpo y el movimiento. Es por tanto pertinente revisar los nuevos estudios en Neurociencia y su implicancia en la educación, especialmente los fundamentos teóricos sobre la cognición incorporada o aprendizaje 
encarnado (Skulmowski, 2018). El cuerpo, la experiencia y la acción son parte fundamental en todo acto de conocimiento. Así el cuerpo en su conjunto está comprometido en el fenómeno de percibir, y la percepción se entiende como acción corporizada.

Nos hemos apoyado en estas teorías para afirmar que las personas con ceguera, pueden complementar su experiencia multisensorial con información viso-espacial. Esta información se genera a partir de una imagen técnica de índole táctil, que les permite recorrer los límites de las formas en relieve, a través del tacto en movimiento, y que les habilita a recrear e interpretar las formas como producto de la oposición entre el espacio generado por estas formas y el vacío. En relación a esta oposición, compartimos con Sancho Madrilejos que: "El vacío necesita de la forma, «llama a la forma» para generar espacio [...] como algo definido, generado, que surge del enfrentamiento entre este vacío y la forma" (Madrilejos, 1993: 7).

De este modo la persona ciega al habitar un espacio desconocido, experimenta constantemente la sensación de vacío en lo que se le presenta, más allá de la extensión de sus brazos o el alcance de su bastón. Este gran vacío sin embargo está colmado de otras sensaciones distantes, como los sonidos y los aromas, los cuales pueden ser rearticulados en un espacio que adquiere formas, al tallarse la materia, en este caso el krión, generando figuras en relieve que le permiten completar la escena en su imaginario.

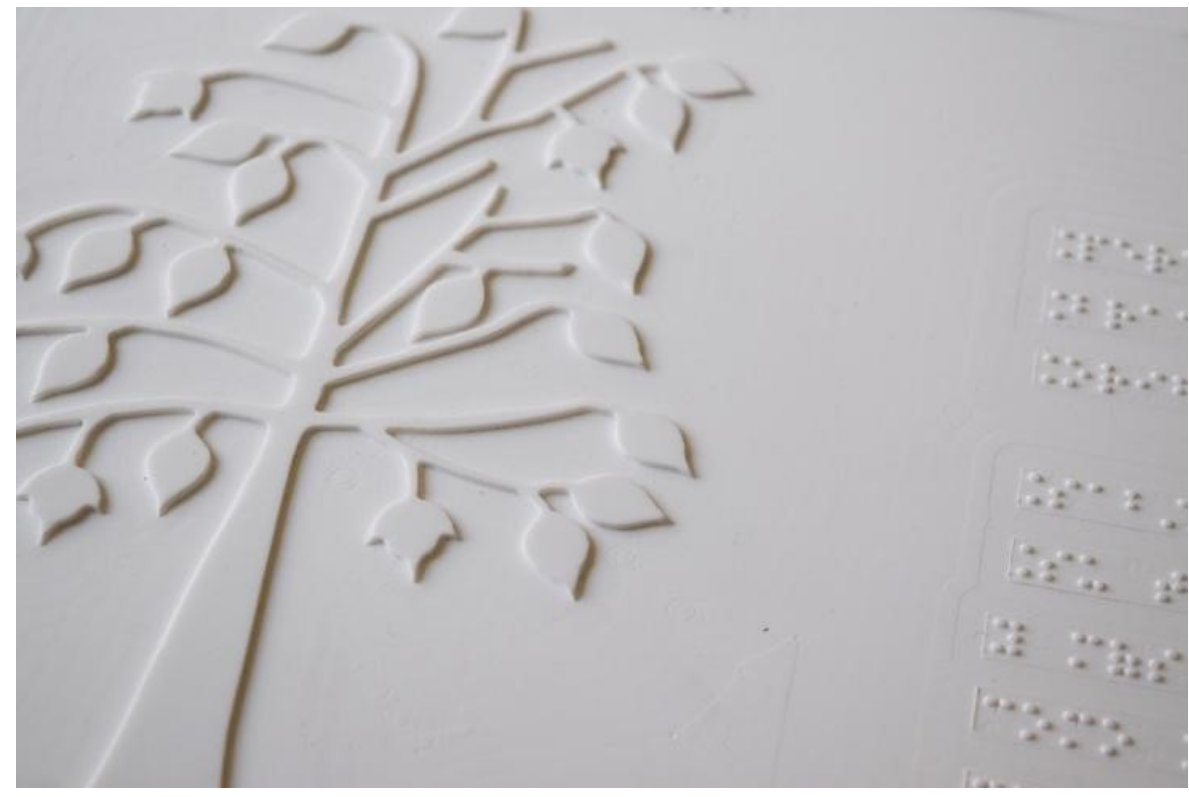

Figura 1. Imagen táctil. Fotografía: Pilar Correa S. 
La acción de la mano define la oquedad del espacio y a la vez la solidez de las cosas que la llenan. Focillon, 2010: 124.

Para nuestros sentidos, el punto es el principal, el único puente entre la palabra y el silencio. Kandinsky, V., 2003: 21.

\section{El acto de diseñar, una propuesta para otros...}

Haciéndonos parte del reclamo por más inclusión y diversidad, desde la disciplina del diseño debemos considerar las diferentes formas de recoger información que tienen nuestros posibles usuarios. A esto último se suma el hecho que hace más de tres décadas se han generado acuerdos internacionales, subscriptos por diferentes organismos, y promulgado leyes en distintos países, también en Chile desde el año 2010 (Ley No 20.422), que tienden a la eliminación de todas las formas de discriminación de la discapacidad, y hacen que en la actualidad este sea un tema de gran relevancia. En este contexto socio cultural emergen nuevas metodologías para el diseño como: el diseño para todos, diseño universal, diseño accesible, entre otras, que requieren no solo tener las intenciones, sino generar los conocimientos y además fortalecer el uso de herramientas comunicacionales apropiadas. En consecuencia, el reconocer que la imagen táctil tiene una realidad teórica y práctica más allá de su existir para los ojos, plantea de inmediato nuevos retos, no tan solo para el diseño, sino que también para otras disciplinas, entre ellas la cartografía. Esto genera una gran oportunidad para indagar hasta dónde se puede llegar para incorporar al mundo de la imagen, a aquellos que, por la edad, enfermedad o porque les ha sido vedada la visión ocular, no pueden integrarse a él.

Este acceso a las imágenes que no se pueden ver, ya desde su enunciado, aparece como si fuera un arte de magia, o como un oximorón sorprendente al tiempo que desafiante. Y es a través del concepto de magia que nos encontramos nuevamente con Flusser, el que ya se había fijado en ella en su examen de los distintos estadios de la evolución comunicacional humana. Al articular la relación entre los códigos de la imágenes (bidimensionales) y los textos (históricos), no hace otra cosa que contraponer el mundo de la magia, un mundo en que todo se repite, y todo participa de un contexto significativo, al mundo histórico de la linealidad del texto, en el que nada se repite y todo tiene causas y acarrea consecuencias: “... en el mundo histórico el amanecer es la causa del canto del gallo, mientras que en el mágico el amanecer significa el canto del gallo y el canto del gallo significa el amanecer. El significado de las imágenes es mágico" (Flusser, 2001: 12). Sin embargo, hay que reconocer el aspecto inevitable de esta magia, como un desprendimiento casi natural del uso de los códigos y sus resultados en cuanto a conocimientos y apreciación del entorno. Conocer el 
mundo a través de las imágenes, incluidas las que se pueden tocar, puede ser engañoso, y en este sentido convertirse en experiencias mágicas, pero no por ello menos comunicativas, sino que incluso más. De esta manera, como lo indica Flusser sobre la labor correctiva o explicativa de los textos sobre las imágenes, las láminas táctiles no funcionan sin un apoyo de textos, en este caso cifrados en el sistema Braille, que precisan el sentido y el significado de lo que los usuarios "ven" con las manos.

No debemos olvidar que las imágenes son las que nos permiten mediar con el mundo, con el exterior de nuestro ser. Esta mediación la hacemos, como en la escena aludida, con la tonada del gallo, entre otros estímulos; sin embargo, el espacio como escenario, como forma, no lo podemos construir sino en base a la información espacial que recoja la vista o el tacto en movimiento. Traemos a colación al respecto lo expuesto por Focillon en su libro La vida de las formas, en que planteó que:

A veces la forma ejerce una especie de atracción sobre diversos sentidos; o, más bien, se presenta como un molde ahuecado en donde el ser humano vierte una tras otra diferentes materias que se someten a la curvatura que las presiona y adquieren así una significación nueva (2010: 16).

Es por esto que la mediación técnica entre el espacio de "allá" cuatridimensional, y el espacio abstraído de las láminas en dos dimensiones, de carácter táctil, nos sirve para comprender la construcción imaginativa del espacio vivido por las personas con ceguera.

Por ello es además importante identificar los diversos modos en los cuales se puede colaborar con las capacidades de una persona con ceguera, para abstraer las cuatro dimensiones de un objeto en el paisaje mediado por una imagen técnica bidimensional, con diferentes relieves, que le transmita las propiedades espaciales de la escena. Entonces se debe precisar cuál es el punto de encuentro, de choque, de contacto de la información visual con su perceptor ciego. Es decir, descifrar los factores fisiológicos, topológicos y relacionales que se deben suministrar; por tanto, diseñar, mediar entre la información visual y la percepción háptica, para que se pueda procurar un acoplamiento estructural por medio de las imágenes táctiles. Teniendo en consideración que la forma de conocer el espacio, sin el sentido de la visión, es habitándolo con su propio cuerpo o interpretándolo a través de sus manos. Esta interpretación del espacio no se logra a través de los medios tecnológicos, ni con una descripción del mismo por medio de un relato oral o escrito, si no se tiene la facultad de ver o tocar. El resto de los sentidos no pueden configurar la escena base, no permiten caracterizar el vacío generado en condiciones de oscuridad, y no suplen las limitaciones del cuerpo en el espacio distal. La percepción del espacio en dos o tres dimensiones solo se logra a través de la percepción de las diferencias lumínicas de la escena, o a través del vivenciar el escenario a través del cuerpo y del movimiento, explorándolo con los sentidos apropiados. Esta exploración es comparable a lo que 
Flusser llama "escaneo", y se realiza con la acción de los ojos (movimientos sacádicos) o de las manos (acción háptica). Las láminas táctiles que aquí presentamos, estimulan el "escaneo" de las representaciones que contienen a través de la percepción háptica, estableciendo una relación espacio-tiempo al interior de la experiencia vivida por el sujeto.

De este modo, como el mismo Flusser afirmó en relación a la aparición de las imágenes técnicas, las táctiles estarían cumpliendo una función similar, que sería "liberar a sus receptores por magia de la necesidad de un pensamiento conceptual" (2001: 20). Se debe aclarar que, para este autor, la contienda entre las imágenes técnicas y el pensamiento conceptual, cabe dentro del conflicto evolutivo y comunicacional que justificó la aparición de estas imágenes, como un evento que hizo nuevamente relevantes a las imágenes en relación a los textos, cuya extrema dificultad y abstracción los arrastró al exceso de la "textolatría". Lo destacable en este punto es que las imágenes táctiles como imágenes técnicas, no sólo cumplen con liberar de este modo mágico a su receptor del pensamiento puramente conceptual, sino que al mismo tiempo lo vienen a liberar de su adolecer de imágenes, apropiadas a sus condiciones perceptuales. En resumen, se trataría de una doble liberación.

Esta propuesta de construcción para lo que podríamos identificar como "imágenes técnicas-táctiles bidimensionales", nos reclamó la búsqueda de modernos materiales para ampliar las propuestas de diseño, que pasaran a formar parte de nuevos soportes comunicacionales.

En este trabajo se expone una propuesta de diseño, investigación y desarrollo al alero del proyecto de investigación apoyado por el Instituto Panamericano de Geografía e Historia IPGH-OEA, realizado en el Centro de Cartografía Táctil (CECAT) de la Universidad Tecnológica Metropolitana, en torno a las ilustraciones científicas táctiles y la búsqueda de un material para ser ubicadas en espacios públicos y en museos. Como primera aplicación se desarrolló el proyecto de placas educativas inclusivas de flora, en el Parque Inés de Suárez de la Ilustre Municipalidad de Providencia, en Santiago de Chile.

Se buscó un material que fuera cálido al tacto y que no variara su temperatura en exceso con los cambios climáticos extremos, además de ser duradero y de fácil mantención. El material seleccionado fue el krión, el que además de tener estas características es resistente, antibacteriano y particularmente atractivo al tacto como a la vista.

Las láminas táctiles que conformaron esta muestra, que se desarrollaron con el objetivo suplementario de estimular, en todo tipo de persona, la vivencia estética de los árboles y arbustos que habitan en el parque Inés de Suárez de la comuna de Providencia, son el resultado de una rigurosa investigación académica, que anidó el deseo de derribar fronteras para una mayor inclusión. De esta manera, las imágenes graficadas táctilmente permiten apreciar la gran variedad de formas que emergen de 
la naturaleza. La ausencia de color, en este caso, deja desnuda su estructura, permitiéndonos disfrutar a todos, de sus sinuosidades, así como de sus llenos y vacíos, y de este modo modelar su existencia en nuestra imaginación.

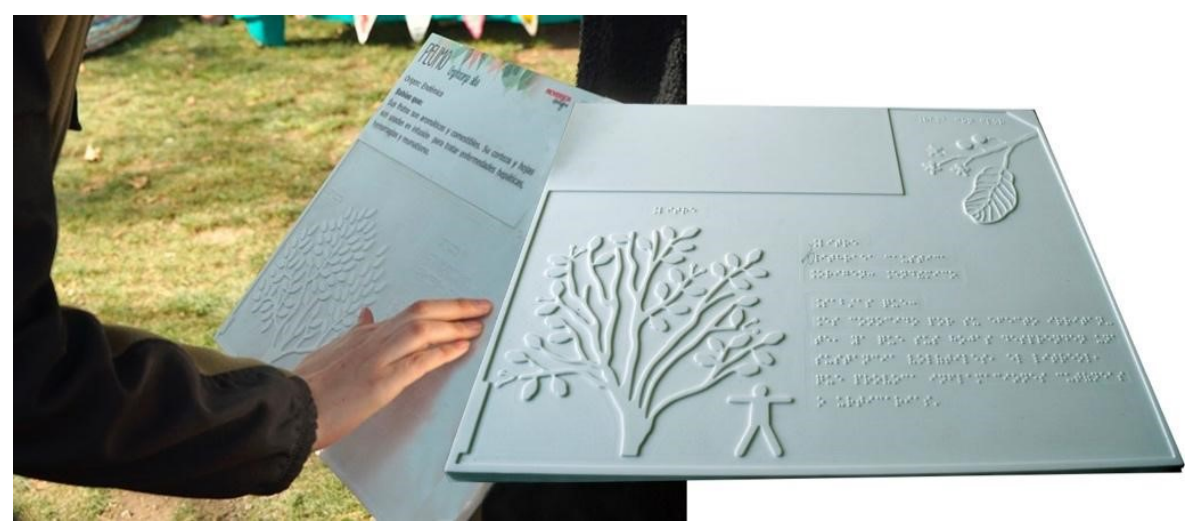

Figura 2. Placas gráfico-táctiles del Parque Inés de Suárez. Fotografia: Pilar Correa Silva.

El tamaño, la proporción, la escala y los detalles de cada especie desarrollados en estas láminas, permiten, a través de la experiencia, distinguir su ser corpóreo y su relación con el usuario. Las láminas fueron diseñadas especialmente para que las personas con ceguera puedan verlas a través de sus manos, y los que gozamos de la visión, apreciar el empleo de los otros sentidos. Este tipo de lenguaje gráfico también es capaz de contarnos pequeños relatos, representando el efecto del viento en las formas que adquieren los árboles, y si estos cambian o no de follaje cada año dejando caer sus hojas. Nos cuentan además sobre las flores, frutos y/o semillas que contienen, advirtiéndonos además sobre su tamaño en relación al cuerpo humano como unidad de medida.

El proyecto, desarrollado por el equipo del Centro de Cartografía Táctil de la Universidad Tecnológica Metropolitana, consistió en el diseño e instalación de 35 placas educativas inclusivas de flora existentes en el Parque, y que presentan una cartografía temática de cada una de las especies seleccionadas, entre las que se encuentran: acer, jaranda, gravillea, liquidambar, olmo americano, sequoia, álamo blanco, casuarina, tuya oriental, pata de vaca, entre otras.

El tamaño del soporte de cada lámina es de $45 \times 37 \mathrm{cms}$. Se estableció teniendo en consideración la espacialidad de las imágenes a representar, la cantidad de información a colocar en Braille y especialmente cualificando el tamaño de los instrumentos de recogida de información, en este caso las manos. Se diseñaron así de modo que ambas extremidades en conjunto puedan ir recorriendo los contornos de cada una de 
las especies, y configurar de esta manera la unidad a partir de las partes. Por último, es importante señalar que la interpretación las de imágenes táctiles, al igual que los mapas, requieren habilidades para su comprensión, y depende de tres factores:

- el dominio de los esquemas cognitivos espaciales,

- las condiciones de legibilidad del material presentado,

- la destreza que permita transformar el estímulo táctil en información topológica eficiente (Barrientos et al., 2017: 57).
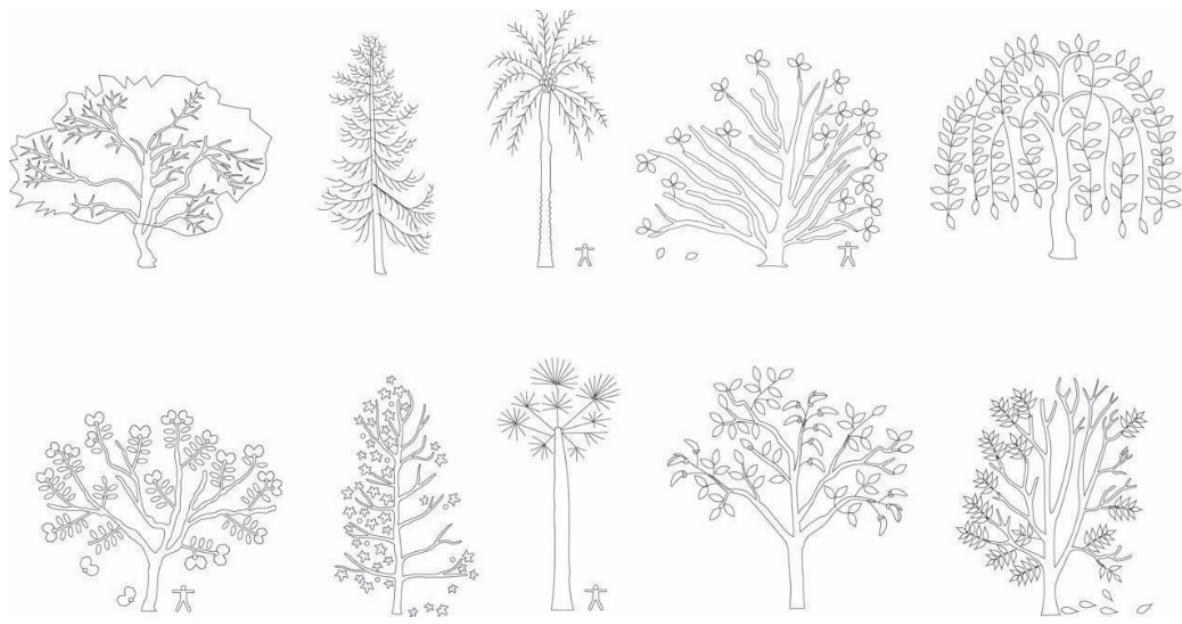

Figura 3. Ilustraciones de Claudia Camacho Briceño y Macarena Ponce Saavedra. Centro de Cartografía Táctil, UTEM.

Cabe mencionar que este trabajo fue realizado considerando los requerimientos que las personas con ceguera han individualizado en las evaluaciones realizadas a imágenes táctiles, como resultado del trabajo doctoral realizado en la Universidad de Barcelona en el año 2008 (Correa, 2011), y los obtenidos de la investigación Fondecyt en los años 2012 y 2013, (Correa, 2014, 2017). Además de lo anterior, estas láminas fueron evaluadas por un experto ciego y una educadora diferencial.

\section{La dimensión estética en el paisaje táctil}

Una aproximación estética a las imágenes elaboradas para ser tocadas, a través de diseños y técnicas que estimulan el tacto de las personas ciegas o con baja visión, nos ofrece un desafío muy particular, similar en aspecto al que tiene que ver con la justificación teórica de una imagen como esta. En este sentido es el mismo concepto de imagen, asociada con la no visión o con sus dificultades, la que nuevamente despierta 


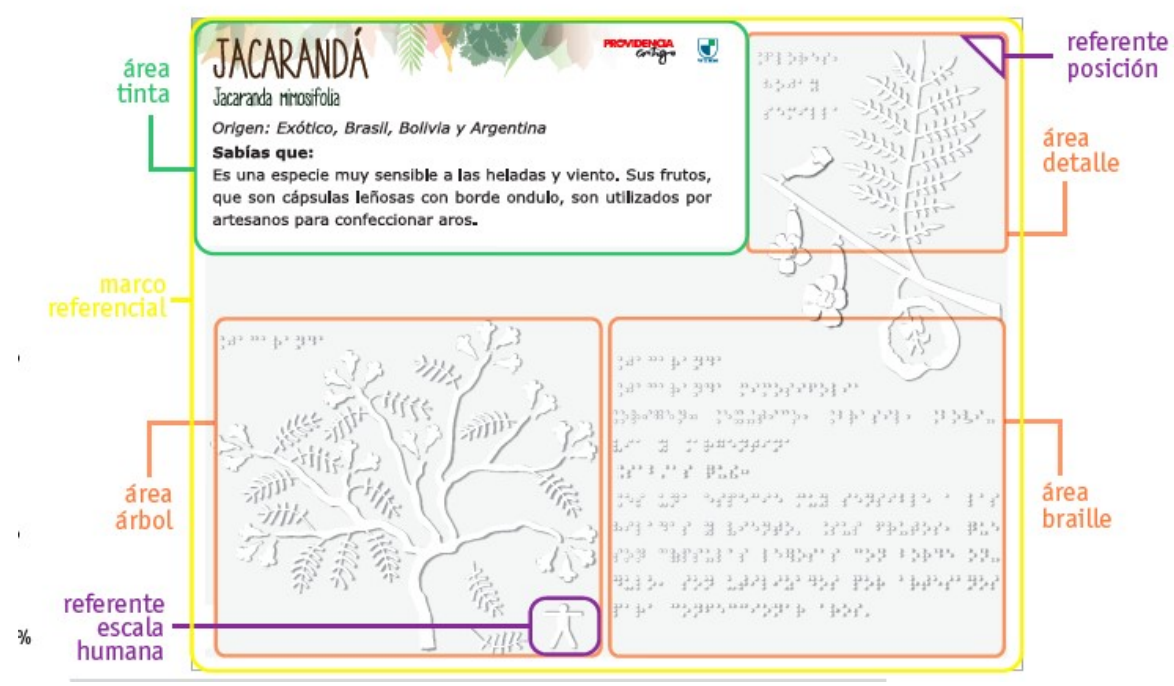

Figura 4. Autor: Macarena Ponce Saavedra, Centro de Cartografía Táctil, UTEM.

sospechas y prejuicios que con mucho cuidado, hay que empezar a despejar. Y es que la historia de las imágenes, especialmente las que han sido producidas o dedicadas a un propósito artístico, o las que han sido apreciadas o servido de estímulo estético en el contexto de la cultura occidental, como las impresiones que vienen de la naturaleza o el arreglo de los ambientes humanos, está condicionada por las formas y los estudios sobre el ver, como una acción eminentemente ocular.

Una discusión sobre las características estéticas de la imagen táctil debería hacerse cargo de la anterior condicionante histórica, y permitir, con ella y a pesar de ella, una oportunidad para comprender el mecanismo por el cual ocurre una experiencia similar provocada por estas láminas, que pretenden también una forma nueva de apreciación y gusto por el paisaje, sólo que en términos no oculares.

No obstante, podríamos adelantar algunas consideraciones sobre el experimentar el gusto en general, como una manera de acopiar ideas y puntos de vista que puedan ayudar a esclarecer el estatuto estético de las imágenes táctiles. En este curso es posible aprovechar el punto de vista de Hery Van Lier (1971) y sus minuciosas observaciones sobre la estética aplicable al caso de los objetos, en sus diferentes apariciones culturales y espacio-temporales.

Comenzando con alguna de estas observaciones, podemos destacar lo indicado por el autor sobre el lugar ocupado por la experiencia estética de los objetos culturales en su dinámica relación con lo humano, que es justamente el último. Le anteceden 
una serie de niveles de experiencia y apropiación, claramente más importantes en la economía social del objeto. Según Van Lier respecto al estadio estético del objeto:

Aunque ocupe el último puesto, es algo así como una coronación, y hasta nos atreveríamos a decir una verificación última. Es en él donde el sistema fundado en la búsqueda de la unidad, la correspondencia entre lo abstracto y lo concreto, se cierra. El orden estético supone un separarse del mundo (separación del lenguaje y de la operación ascéticos), pero consume el retorno al mundo. Es aquello por lo cual la distancia se colma sin anularse (Van Lier: 147-148).

Este último lugar, aunque lo postrero muchas veces represente comúnmente una pérdida o un sobrante, tendría una importancia fundamental para la constitución completa del objeto, en este caso identificado con occidente. Sin la estética el mismo quedaría trunco de sentido, porque como experiencia culmina y redondea el proceso cultural que le da cabida. No es por demás entonces, que estas notas sobre lo estético de las imágenes táctiles cierren este artículo.

En consecuencia, podríamos subrayar una idea que se desprende misteriosa de la cita anterior, y que concuerda de alguna manera con la idea del final como lugar de la apreciación sensible. Este punto se refiere al "separarse del mundo" pero a su vez "el retorno al mundo". Esta afirmación implica, en su primer aspecto, aceptar que al finalizar cualquier producción cultural — todas ellas reducibles a formas de expresión - lo que se obtiene es una entidad nueva, que al no existir antes nos independiza del entorno natural (nos separa). Recordaremos que esta conclusión es concordante con lo que Flusser indica acerca de la evolución multidimensional del fenómeno de la comunicación, esto es, el desarrollo de un constante y progresivo abstraerse del mundo

El segundo aspecto que remarcamos comprende "el retorno al mundo", el cual debe ser explicado como fundamento del accionar estético. Este segundo aspecto conlleva particulares movimientos de la sensibilidad que el autor define como "inmediaciones totalizadoras" (148). En ellas las distinciones entre objeto y sujeto se diluyen, para dar paso a un tipo de percepción global, de carácter contemplativo y desinteresado, que remata en una "continuidad saturante" (148), y en una suerte de comunión identitaria, aunque momentánea, de ambos elementos.

De este modo, en este accionar dialéctico de dos movimientos, uno que nos independiza del mundo (convirtiendo a nuestros objetos en entidades aisladas), y otro que nos devuelve al mundo (desde la contemplación y la continuidad sujeto-objeto), también se podría concebir la suerte del estatuto estético de las imágenes táctiles, en su calidad indiscutible de imágenes-objeto.

Un desafío interesante en esta parte de la discusión, es el análisis de la pertinencia estética de la imagen táctil, ya que, al adolecer de la participación visual, establece características nuevas en el tipo de inmediación contemplativa comprometida al mo- 

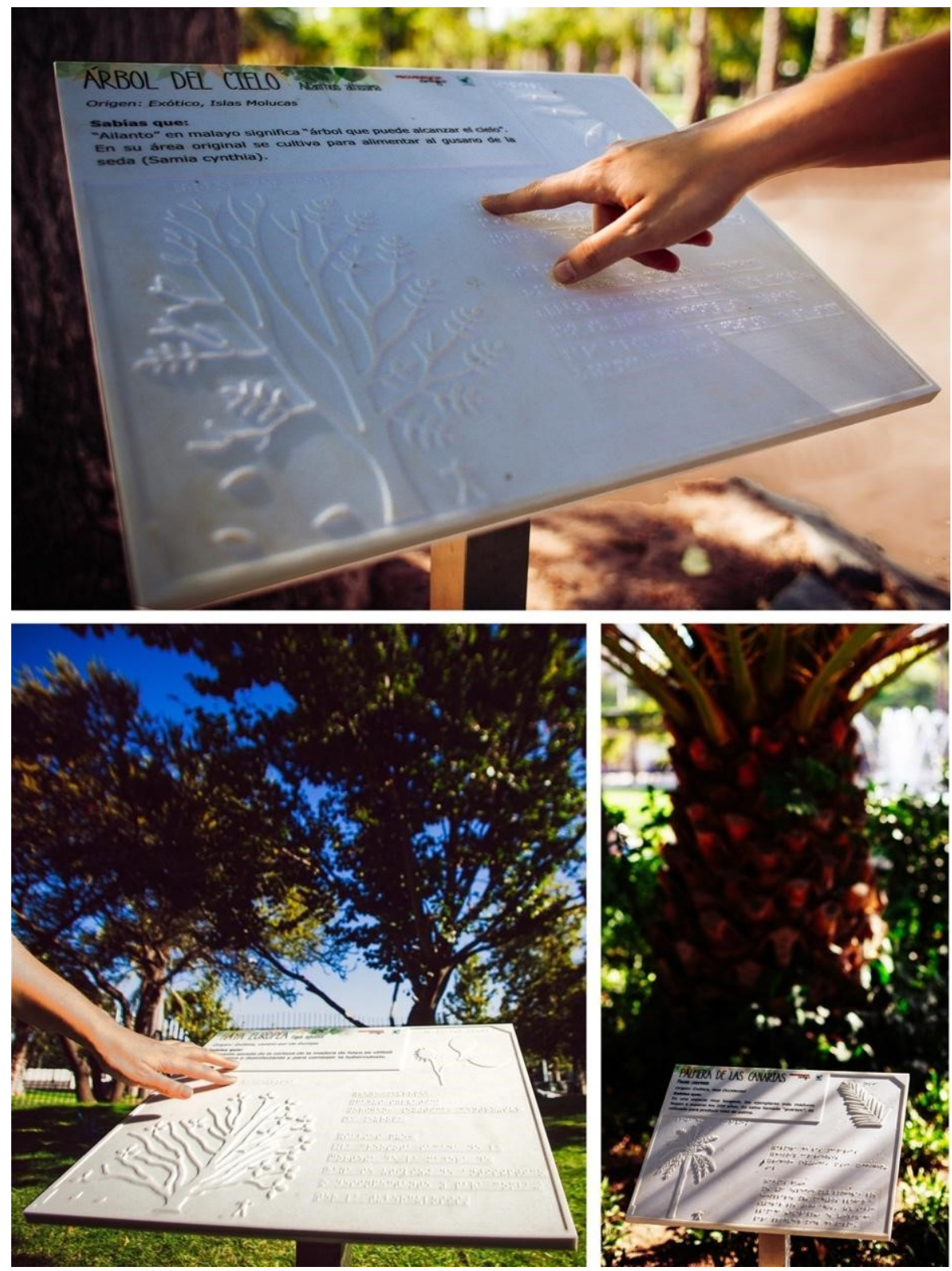

Figura 5. Fotografía: Pablo Fuente Selman, Vicerrectoría de Transferencia Tecnológica y Extensión, UTEM. 
mento de la continuidad sensible. Lo mismo es saber si esta continuidad es complementaria en la reducción de la impresión de "vacío" que acompaña frecuentemente la percepción de las personas con ceguera y que las mismas imágenes táctiles, en su dominio informativo y comunicativo, anteriormente ya han logrado remitir.

Por último, y en una sintonía más fina, por las características de las inmediaciones sensibles permisibles a través de la lectura del tacto activo, podríamos investigar de qué manera se articula el retorno al mundo a través de estas particulares imágenes. Este estudio, además, debería partir suponiendo que este retorno es semejante al que podemos esperar acontece desde la visualidad, en la que la continuidad objeto-sujeto no sólo compromete la salida del sujeto al objeto, sino que a través del él, al entorno que los contiene a ambos.

\section{Conclusiones}

El diseño y la producción de láminas que representan una codificación háptica del entorno natural, adaptada como imagen táctil a las capacidades sensibles e interpretativas de un receptor ciego, da cuenta de las posibilidades que se abren para la generación de diversos instrumentos y medios de aprendizaje y comunicación inclusivos y apropiados a las necesidades de este y otro tipo de usuarios. También posibilitan la exploración y el empleo de nuevos materiales, como el Krion, en orden a su aprovechamiento como soporte apropiado de lectura en espacios públicos o abiertos.

El análisis de estas imágenes permite también una reflexión sobre el estatuto técnico que las sustenta. Su imprescindible adaptación a las capacidades sensibles y perceptuales del usuario, hace que su mismo tránsito al lenguaje de programación del router de desbaste se haga cada vez más preciso y adecuado, abstrayendo lo necesario de su modelo natural (en este caso los especímenes arbóreos y florales).

De esta manera, al conocimiento y goce del perceptor preparado por su sensibilidad y manejo de los entornos sin luz, se le ofrece la oportunidad de acercarse a la experiencia del paisaje. Este acercamiento se prevé no sólo como uno de carácter didáctico sino que derechamente sensible y personal, por tanto subjetivo y estético. Se presupone a su vez que esta experiencia no debería ser menos o esencialmente distinta a la que ocurre con el sujeto vidente. La inmediación totalizante como vivencia estética es de dominio universal, y en este caso sólo aguarda la mediación instrumental e imaginaria apropiada, aquí representada por la imagen táctil.

\section{Bibliografía}

Barrientos, T.; Coll, A. y Huentelemu, V. (2017). Enseñando y aprendiendo el espacio geográfico por medio del tacto: orientaciones metodológicas, Centro de Cartografía Táctil (CECAT), Editorial Universidad Tecnológica Metropolitana, Santiago de Chile. 
Becker, C. (2015). "Imágenes técnicas y los órdenes del saber", Troncoso, V\&G. González, G. (eds.), Arte + Archivo. Producción, reflexiones, desplazamientos, Santiago de Chile, Ediciones Departamento de Artes Visuales, Facultad de Artes, Universidad de Chile, pp. 120-138.

Berque, A. (1997). "En el origen del paisaje", Revista de Occidente, núm. 189, pp. 7-21.

Blanco, F. y Rubio, M. (1993). "Percepción sin visión”, capítulo 3, en Rosa, A. y Ochaita, E. (comps.), Psicología de la ceguera, Madrid: Alianza Editorial.

Correa, P., (2015). "Dis-capacidad, diseño-capacidad. Una reflexión sobre su facultad de mediación”, Revista IconoFacto, vol. 11, Medellín, Colombia, pp. 86-95. (2017). "La imagen táctil: un aporte al fenómeno del conocimiento del espacio", Revista Dilemas contemporáneos: Educación, Política y Valores I, año IV, núm. 2, México. Recuperado de <http://files.dilemascontemporaneoseducacionpoliticayvalores.com>.

(2014). "Toward a construction and a reading model of tactile graphics for educational purposes", Les Doigts Qui Rêvent-Journal Terra Haptica, Talant, France, pp. 23-32.

, (2011). Imágenes que podemos tocar, Santiago de Chile, Editorial Universidad Tecnológica Metropolitana.

Focillon, H. (2010). La vida de las formas seguida de elogio de la mano, Fernando Zamora (trad.), México, Editorial Universidad Nacional Autónoma de México.

Flusser, V. (2001). Una filosofia de la fotografía, Madrid, España, Síntesis.

- (2012). "Una nueva imaginación”, La Fuga, 14. Recuperado de $<$ http://2016.lafuga.cl/una-nueva-imaginacion/532>, consultada el 11 de enero de 2019.

- (2016). Vilém Flusser y la Cultura de la Imagen. Textos escogidos, Breno Onetto (trad.), Chile Editorial, Ediciones UACh.

Gombrich, E.H. (1979), Arte e ilusión, Barcelona, Gustavo Gili. , (2000), La teoría del arte renacentista y el nacimiento del paisajismo, en Gombrich, E.H., Norma y Forma. Estudios sobre el arte del Renacimiento, 1, Madrid, España, Debate, pp. 107-121.

Gubern R. (1996). Del bisonte a la realidad virtual, La escena y el laberinto Barcelona, Editorial Anagrama.

Gumtau, Si (2013). "Crítica del diseño de la interacción háptica en un contexto histórico ¿Qué sucede hoy con el tacto?”, en Allen, J. (coord.), La materia de los medios [nodo en línea], Artnodes, núm. 12, pp. 11-18. doi: 10.7238/a.v0i12.1596. Kandinsky, Vassily (2003), Punto y linea sobre el plano, Buenos Aires, Andrómeda. Luria, A. (1981). Sensación y percepción, Barcelona: Fontanella, (1a. edición 1975). Madridejos, S. y Sancho J. (1993). "La paradoja del vacío”, Revista Circo, núm. 6, Madrid. 
Maturana, H. y Varela, F. (1984). El árbol del conocimiento, Santiago de Chile, Lumen.

Merleau-Ponty, M. (1997). Fenomenología de la percepción, 4a. ed., Barcelona, Península.

Onetto, B. (2016). Vilem Flusser y la cultura de la imagen. Textos escogidos, Santiago de Chile, Editorial Ediciones UACh. Colección Austral Universitaria de Ciencias Sociales, Artes y Humanidades.

Sami-Ali. (1984). Lo visual y lo táctil, Ensayo sobre la psicosis y la alergia, Buenos Aires, Amorrortu.

Sartre, J.P1. (1997). Lo imaginario, Buenos Aires, Losada.

Sartori, G., (1998). Homo Videns. La sociedad teledirigida, México, Taurus.

Skulmowski A, Rey GD. (2018). "Embodied learning: introducing a taxonomy based on bodily engagement and task integration. Cognitive Research: Principles and Implications"; vol. 3, núm. 1, p. 6. doi: 10.1186/s41235-018-0092-9

Van Lier, H. (1971). "Objeto y estética", en Moles. A. (ed.), Los Objetos, Buenos Aires, Argentina, Tiempo Contemporáneo, pp. 129-152.

Varela, F. (2005). Conocer, Barcelona, Gedisa, [Primera edición 1988].

Varela, F. Thompson, E. y Rosch, E. (2005), De cuerpo presente, Barcelona, Gedisa. 